Influence of

\title{
Dilution Rate on NAD(P) and NAD(P)H Concentrations and Ratios in a Pseudomonas sp. Grown in Continuous Culture
}

\author{
By A. MATIN* AND J. C. GOTTSCHAL \\ Department of Microbiology, University of Groningen, \\ Haren, The Netherlands
}

(Received 23 September 1975)

\begin{abstract}
SUMMARY
A freshwater Pseudomonas sp. was grown in continuous culture under steadystate conditions in L-lactate-, succinate-, glucose- or ammonium-limited media. Under carbon limitation, the NAD $(H)$ (i.e. NAD + NADH) concentration of the organisms increased exponentially from approximately 2 to $7 \mu \mathrm{mol} / \mathrm{g}$ dry wt as the culture dilution rate $(D)$ was decreased from 0.5 to $0.02 \mathrm{~h}^{-1}$. Organisms grown at a given $D$ in any of the carbon-limited media possessed very similar levels of $\mathrm{NAD}(\mathrm{H})$. Therefore, under these conditions, cellular $\mathrm{NAD}(\mathrm{H})$ was only a function of the culture $D$ and was independent of the nature of the culture carbon source. $D$ had no influence on the NAD $(H)$ content of cells grown under ammonium limitation. In contrast, cellular NADH concentration was not influenced by $D$ in carbon- or ammonium-limited media. In L-lactate-limited medium, bacteria possessed $0 . \mathrm{I} 4 \mu \mathrm{mol} \mathrm{NADH} / \mathrm{g}$ dry wt; very similar levels were found in organisms grown in the other media. The results are consistent with those of Wimpenny \& Firth (I972) that bacteria rigidly maintain a constant NADH level rather than a constant NADH:NAD ratio. NADP(H) (i.e. NADP + NADPH) and NADPH levels were also not influenced by changes in the culture carbon source or in $D$; in L-lactate-limited medium these concentrations were 0.97 and $0.53 \mu \mathrm{mol} / \mathrm{g}$ cell dry wt, respectively. The NADPH: $\mathrm{NADP}(\mathrm{H})$ ratio was much higher than the $\mathrm{NADH}: \mathrm{NAD}(\mathrm{H})$ ratio, averaging $55 \%$ in carbon-limited cells.
\end{abstract}

\section{INTRODUCTION}

Nicotinamide nucleotides occupy a central place in the energy transforming and oxidation-reduction reactions of a cell and probably play an important part in their regulation. The indispensable nature of these cofactors to various pathways indicates their potential importance in biological control, and there is substantial evidence that these cofactors (Sanwal, 1970) or the ratio between their reduced and oxidized forms (Barnes, McGuire \& Atkinson, 1972; Dionisi et al., 1973; Pina et al., 1973) act as allosteric effectors in modulating enzyme activities.

Direct measurements of intracellular NAD $(\mathrm{P})$ and $\mathrm{NAD}(\mathrm{P}) \mathrm{H}$ concentrations and ratios have revealed some striking constants. Throughout a threefold change in the total nicotinamide nucleotide content of Neurospora crassa, the NAD: NADP ratio remained approximately 7 , the $\mathrm{NADH}: \mathrm{NAD}(\mathrm{H})^{\prime}$, ratio', approximately 0.35 , and $\mathrm{NADPH}: \mathrm{NADP}(\mathrm{H})$ ratio approximately 0.65 (Brody, 1972); and although the total nicotinamide nucleotide content of two cell lines of mouse fibroblasts was significantly different, their NADH : NAD

* Present address: Department of Medical Microbiology, Stanford University School of Medicine, California 94305, U.S.A. 
ratios were very similar (Schwartz et al., I974). Studies with bacteria also suggest that their NAD : NADP ratios might be rigidly controlled. A $50 \%$ increase in the intracellular nucleotide pool in Escherichia coli, attained by an increase in medium niacin concentration, did not alter this ratio, which remained at 3: I (McLaren, Ngo \& Olivera, I973), and three $E$. coli strains which differed in their total nicotinamide nucleotide content possessed similar NAD : NADP ratios (Manlapaz-Fernandez \& Olivera, 1973). However, bacteria seem to differ from eukaryotic organisms in that a constant NADH level rather than a constant NADH : NAD ratio was maintained in three bacteria under different growth conditions (Wimpenny \& Firth, 1972).

In studies on the effect of dilution rate, i.e. specific growth rate, on various aspects of bacterial physiology (Matin, Grootjans \& Hogenhuis, 1976), the total NAD concentration of a Pseudomonas sp. increased considerably as $D$ decreased. Unlike the situation in batch culture, this change occurred under precisely defined steady-state conditions and therefore afforded a more suitable system for investigating the relationship between the concentrations of various forms of nicotinamide cofactors. We have also examined the effect of qualitative changes in bacterial environment on these concentrations with bacteria grown in continuous culture under different limitations.

\section{METHODS}

Culture conditions. The Pseudomonas sp., and the mineral salts base for carbon-limited media, were as described by Matin et al. (1976). This base was supplemented with $\left(\mathrm{g} \mathrm{l}^{-1}\right)$ : L-lactate, I.8; sodium succinate, $2 \cdot 2$; or glucose, I.5. The ammonium-limited medium (carbon source, L-lactate), maintenance of stock cultures and method of continuous cultivation were as described by Matin et al. (1976), except that a chemostat vessel of $200 \mathrm{ml}$ working volume was used.

Nicotinamide nucleotide extraction and assay. A minimum bacterial culture density of $200 \mu \mathrm{g} \mathrm{dry} \mathrm{wt} / \mathrm{ml}$ was required for satisfactory measurement of nucleotide concentrations. The procedure was similar to that of Wimpenny \& Firth (1972). Test tubes (internal diameter, $2 \mathrm{~cm}$ ) containing $2.5 \mathrm{ml}$ of either $0.77 \mathrm{M}-\mathrm{HCl}$, for NAD and NADP, or $0.77 \mathrm{M}-\mathrm{NaOH}$, for NADH and NADPH, were connected to the sampling port of the chemostat and $15 \mathrm{ml}$ of steady-state culture was collected by air pressure. Vigorous shaking ensured a thorough and rapid mixing of the culture with the acid or base. The tubes were then placed in a water bath at $50{ }^{\circ} \mathrm{C}$ for exactly $\mathrm{I} 2 \mathrm{~min}$, cooled to $0^{\circ} \mathrm{C}$ and neutralized by slow addition (accompanied by shaking) of $2.5 \mathrm{ml}$ of either $0.77 \mathrm{M}-\mathrm{NaOH}$ or $0.77 \mathrm{M}-\mathrm{HCl}$, supplemented with Tris-maleate buffer, $\mathrm{pH} 7 \cdot 6$, to a concentration of 0. I I $\mathrm{M}$. The extracts were centrifuged ( $30000 \mathrm{~g} ; 15 \mathrm{~min} ; 4^{\circ} \mathrm{C}$ ), and assayed immediately.

Cofactor concentrations were measured by a sensitive fluorescence method (Cartier, 1968; Wimpenny \& Firth, 1972), thus obviating the necessity for concentrating the bacteria which can lead to significant changes in cofactor levels (Wimpenny \& Firth, 1972). The assay mixture contained (in $\mu$ l): $0.2 \mathrm{M}$-Tris-maleate buffer, $\mathrm{pH} 7.6,150$; resazurin $(2 \mathrm{mM}$ stock solution diluted 10 times with water before use), I50; dipyridyl solution ( $1.1 \mathrm{~g}$ dipyri$\mathrm{dyl} / \mathrm{IO0} \mathrm{ml}$ ethanol, diluted 10 times with water before use), 50; ethanol (for NAD(H) assay) or $\mathrm{I} \%$ glucose 6-phosphate (for NADP(H) assay), I 50; $0.6 \%$ phenazine ethosulphate, 150; alcohol dehydrogenase (EC. I. I. I I ; 500 units/ml solution) or glucose 6-phosphate dehydrogenase (EC. I. I I . 49; 35 units/ml solution), 25; and extract plus water to $3 \mathrm{ml}$.

The rate of increase in fluorescence was recorded using a Perkin-Elmer fluorescence spectrophotometer (type 204), connected to a Servogar (model RE 5I I) recorder. The mono- 

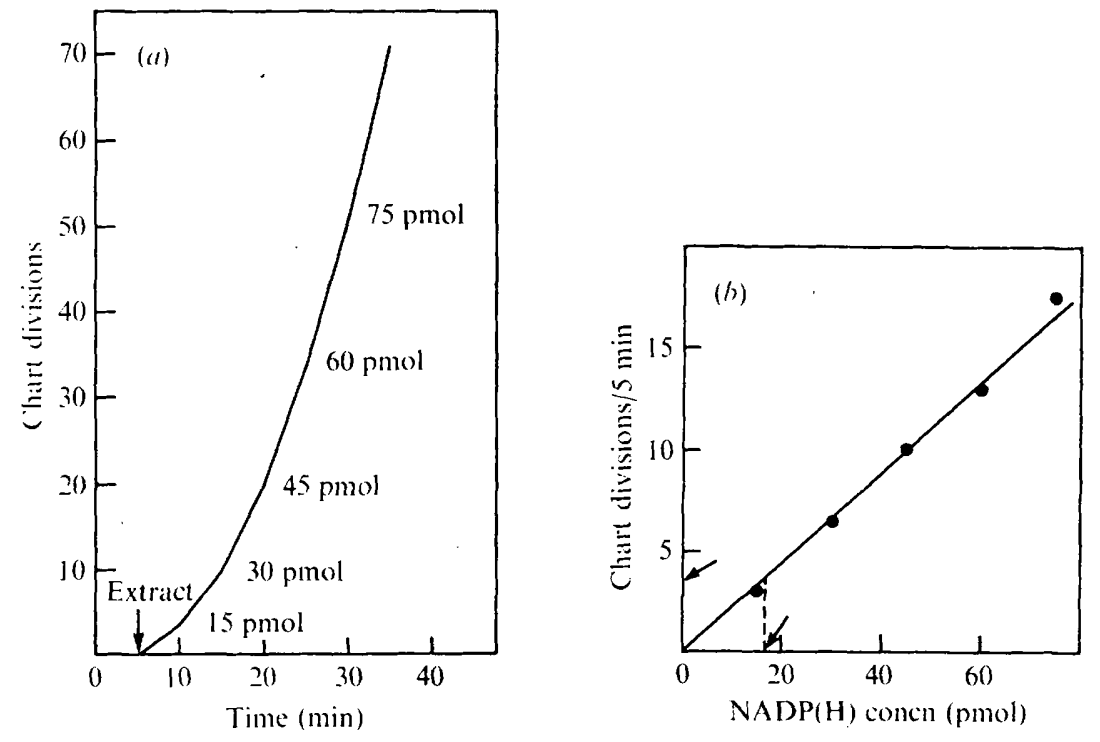

Fig. I. A typical assay for $\mathrm{NADP}(\mathrm{H})$ concentration by the cycling method of Cartier (I968). (a) After measuring the rate of increase in fluorescence caused by addition of the extract, known amounts of $\mathrm{NADP}(\mathrm{H})$ were added to the reaction mixture as internal standards. $(b)$ The curve relating NADP(H) concentration with rate of increase in fluorescence. Arrows indicate the fluorescence and cofactor concentration of the extract.

chromator settings were $560 \mathrm{~nm}$ for incidence and $580 \mathrm{~nm}$ for excitation light. Background increase in fluorescence, measured in the absence of extract, was negligible. Cofactor concentrations were measured by adding internal standards of $\mathrm{NAD}(\mathrm{H})$ (50 to $200 \mathrm{pmol})$ or $\mathrm{NADP}(\mathrm{H})$ ( 15 to $75 \mathrm{pmol}$ ) after the increase in fluorescence caused by the extract had been recorded. Figure I illustrates a typical measurement. Each experimental value in this paper represents an average of measurements on two independently prepared extracts; variation in different extracts for a given value was usually within $10 \%$, and never more than $15 \%$.

The method of extraction employed assumes the bacterial cell to be a single compartment and does not distinguish between free and bound forms of the cofactors. Nevertheless, there is evidence (Hoek \& Tager, 1973; Marshall \& Omachi, 1974) that such measurements can give reasonable approximations of metabolically active pool sizes of nicotinamide nucleotides.

Controls. The effect of different concentrations of acid and base on the extraction of the cofactors was investigated. Increasing the final $\mathrm{HCl}$ concentration in the mixture to $0.25 \mathrm{M}$ did not influence the amount of NAD and NADP extracted from the bacteria, which agrees with the findings of London \& Knight (I966). Similarly, increasing the final $\mathrm{NaOH}$ concentration to $\mathrm{I} M$ had no influence on NADH and NADPH extracted (Table I). Wimpenny \& Firth (1972) used a final concentration of I $\mathrm{M}-\mathrm{NaOH}$ in their extractions, but we preferred $0.1 \mathrm{I} \mathrm{M}$ as it was lower and gave comparable results. To determine if compounds in the bacterial extracts influenced cofactor measurements, known amounts of the different cofactors were added to culture samples and passed through the complete extraction and assay procedure. The recovery was 92 to $110 \%$ (Table 2 ) indicating that the compounds in the extracts did not affect cofactor measurements. It was therefore not necessary to convert NADH into NAD before assay, as was done by Wimpenny \& Firth (1972). Similar experiments showed that alkaline and acid extractions destroyed 90 to $100 \%$ of oxidized and reduced cofactors, respectively. 


\section{Table I. Influence of $\mathrm{NaOH}$ concentration on $\mathrm{NADH}$ and $\mathrm{NADPH}$ extraction}

Samples of a steady-state culture of Pseudomonas sp. were collected, as described in Methods, in $\mathrm{NaOH}$ of the appropriate concentration to give the final concentrations indicated.

\begin{tabular}{|c|c|c|}
\hline \multirow{2}{*}{$\begin{array}{l}\text { Final } \mathrm{NaOH} \\
\text { concentration } \\
\text { (M) }\end{array}$} & \multicolumn{2}{|c|}{$\begin{array}{c}\text { Amount of cofactor extracted from } \\
\text { bacteria }(\mu \mathrm{mol} / \mathrm{g} \text { dry weight })\end{array}$} \\
\hline & NADH & NADPH \\
\hline 0.11 & 0.16 & 0.58 \\
\hline 0.25 & 0.18 & 0.53 \\
\hline 0.50 & 0.13 & 0.52 \\
\hline 0.75 & 0.15 & 0.60 \\
\hline 1.00 & 0.15 & 0.54 \\
\hline
\end{tabular}

Table 2. Recovery of nicotinamide cofactors

A steady-state culture of Pseudomonas sp. was sampled, extracted and analysed, as described in Methods, either directly or after addition to the sample tubes of $1500 \mathrm{pmol} \mathrm{ml}^{-1}$ of the specified cofactor.

$\begin{array}{lccr}\text { Cofactor } & \text { Culture } & \text { Culture + addition } & \begin{array}{c}\text { Recovery } \\ (\%)\end{array} \\ \text { NAD } & 809 & 2122 & 92 \\ \text { NADH } & 56 & 1585 & 102 \\ \text { NADP } & 108 & 1580 & 98 \\ \text { NADPH } & 192 & 1860 & 110\end{array}$

As cofactor concentrations were measured on bacteria plus culture fluid, it was necessary to check if any excreted cofactors in the latter influenced the measurements. For every culture sample analysed, a parallel sample was filtered (filter pore size, $0.22 \mu \mathrm{m}$ ) and the culture fluid extracted and assayed as described. In all instances, the concentration of the cofactors in the culture fluid was negligible.

Chemicals. Alcohol dehydrogenase (code ADHL) was purchased from Worthington Biochemical Corporation, Freehold, New Jersey 07728, U.S.A.; glucose 6-phosphate dehydrogenase (Grade I) from Boehringer, Mannheim, Germany; and other special chemicals from Sigma.

Measurement of dilution rate. Analytical methods and estimation of $D$ were as described by Matin et al. (1976).

\section{RESULTS}

\section{Carbon limitation}

The influence of $D$ on $\mathrm{NAD}(\mathrm{H})$ concentration in Pseudomonas sp. grown in continuous culture in L-lactate-, succinate- or glucose-limited media is presented in Fig. 2(a). At $D$ values close to the maximum specific growth rate of the organism in different media, this concentration ranged between 1.5 and $2.5 \mu \mathrm{mol} / \mathrm{g}$ cell dry wt. As $D$ was decreased in any of the media, the concentration increased, until at 0.02 to $0.03 \mathrm{~h}^{-1}$, bacteria contained 6.6 to $7 \cdot 1 \mu \mathrm{mol}$ cofactor/g dry wt (fivefold increase). Bacteria grown at a given $D$ under limitation of any of the carbon sources possessed similar levels of $\mathrm{NAD}(\mathrm{H})$. When these data were replotted on a semilogarithmic scale (Fig. $2 b$ ), the experimental points clustered around a straight line. Thus, in carbon-limited media, the increase in $N A D(H)$ concentration with decreasing dilution rate appears to be exponential, doubling for each reduction in $D$ of approximately $0.28 \mathrm{~h}^{-1}$. 


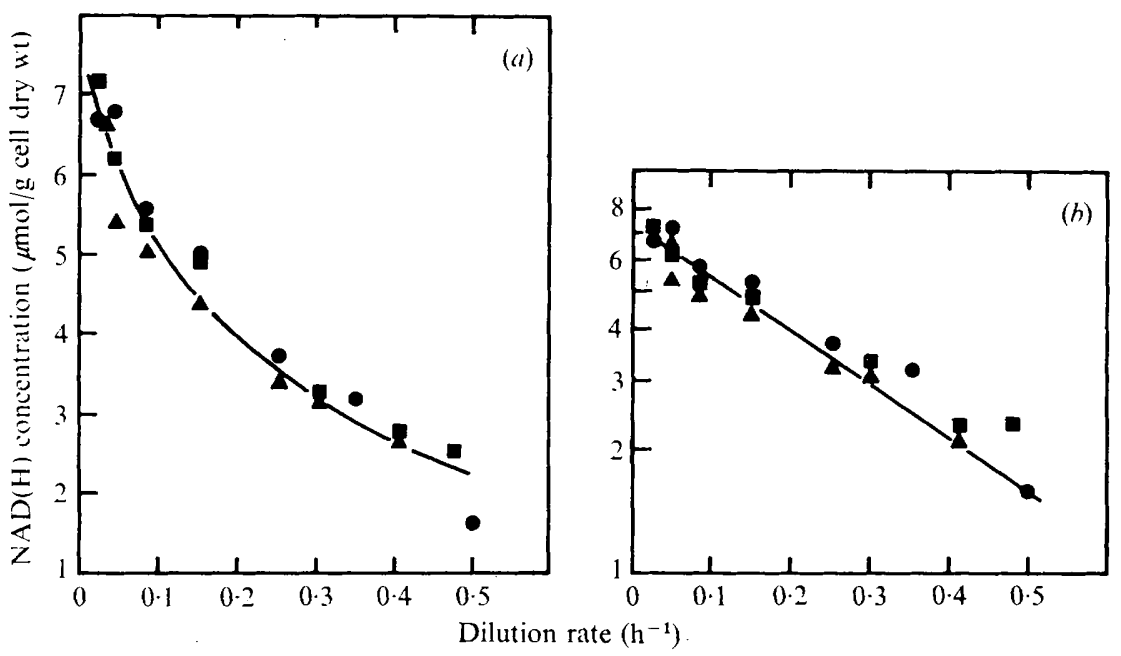

Fig. 2. (a) Cumulative plot of the effect of dilution rate on NAD(H) (i.e. NAD + NADH) concentration of cells of Pseudomonas sp. in carbon-limited media. (b) The same data with NAD(H) concentration of organisms plotted on a logarithmic scale. $\boldsymbol{O}$, L-lactate-limited medium; $\boldsymbol{\Delta}$, succinate-limited medium; $\mathbf{\square}$, glucose-limited medium.

Table 3. Influence of dilution rate on nicotinamide cofactor concentrations and ratios in Pseudomonas sp. grown in continuous culture under L-lactate limitation

Cofactor concentrations ( $\mu \mathrm{mol} / \mathrm{g}$ cell dry wt) and ratios ( $\%$ ) were measured as described in Methods. Figures in parentheses give average values. $\mathrm{NAD}(\mathrm{H})$ indicates $\mathrm{NAD}+\mathrm{NADH}$; and $\mathrm{NADP}(\mathrm{H})$, NADP + NADPH.

Dilution

$\begin{array}{cc}\begin{array}{c}\text { rate } \\ \left(h^{-1}\right)\end{array} & \begin{array}{c}\text { NADH } \\ \text { concn }\end{array} \\ 0.50 & 0.17 \\ 0.35 & 0.13 \\ 0.25 & 0.11 \\ 0.15 & 0.17 \\ 0.08 & 0.10 \\ 0.04 & 0.13 \\ & (0.14 \pm 0.03)\end{array}$

$\begin{array}{cc}\text { NADH } & \text { NADP(H) } \\ \text { NAD(H) } & \text { concn } \\ \text { IO.I } & 0.83 \\ 4 . I & 0.90 \\ 2.9 & 0.97 \\ 3.4 & I \cdot 26 \\ I .8 & 0.83 \\ 2.0 & I .04 \\ & (0.97 \pm 0.16)\end{array}$

\begin{tabular}{c} 
NAD $(H)$ \\
\hline NADP(H) \\
193 \\
356 \\
391 \\
396 \\
675 \\
654
\end{tabular}

NADPH
concn
0.41
0.48
0.56
0.65
0.50
0.58
$(0.53 \pm 0.08)$

\begin{tabular}{c} 
NADPH \\
\hline NADP(H) \\
49 \\
53 \\
58 \\
52 \\
60 \\
56 \\
$(55 \pm 4)$
\end{tabular}

The effect of $D$ on the concentration and ratios of other nicotinamide cofactors in bacteria grown in L-lactate-limited medium is presented in Table 3 . NADH, NADP(H) and NADPH concentrations of the bacteria did not change significantly in response to change in $D$ and were, on average, $0.14,0.97$ and $0.53 \mu \mathrm{mol} / \mathrm{g}$ dry wt, respectively. The NADH : NAD(H) ratio decreased from approximately 10 to $2 \%$ with decreasing $D$ due to the parallel increase in NAD concentration, already described (Fig. 2). For the same reason the NAD $(H)$ : NADP $(H)$ ratio increased from approximately 190 to $650 \%$ with decreasing $D$. The $\mathrm{NADPH}: \mathrm{NADP}(\mathrm{H})$ ratio was much higher than the $\mathrm{NADH}: \mathrm{NAD}(\mathrm{H})$ ratio and averaged $55 \%$. Change in $D$ also had little effect on the concentration of the cofactors in succinateor glucose-limited media (Tables 4 and 5). Bacteria grown in all three media possessed similar levels of the cofactors, indicating that changes in the culture carbon source had no influence on cofactor concentrations.

The NADH concentration found in the present study is considerably lower than the $\mathrm{I}$ to 
Table 4. Influence of dilution rate on nicotinamide cofactor concentrations and ratios in Pseudomonas sp. grown in continuous culture under succinate limitation

Cofactor concentrations ( $\mu \mathrm{mol} / \mathrm{g}$ cell dry wt) and ratios (\%) were measured as described in Methods. Figures in parentheses give average values. Abbreviations as in Table 3.

\section{Dilution \\ rate}

$\left(\mathrm{h}^{-1}\right)$

0.41

$0 \cdot 30$

0.25

$0 \cdot 15$

0.08

0.04

\begin{tabular}{cc} 
NADH & NADH \\
\cline { 2 - 2 } concn & NAD(H) \\
0.15 & 5.8 \\
0.10 & 3.2 \\
0.10 & 2.9 \\
0.16 & 3.7 \\
0.22 & 4.3 \\
0.18 & 3.3 \\
$(0.15 \pm 0.05)$ &
\end{tabular}

\begin{tabular}{cc} 
NADP(H) & NAD $(H)$ \\
\cline { 2 - 2 } concn & NADP(H) \\
$I \cdot 5 I$ & 172 \\
$I \cdot 10$ & 282 \\
$I \cdot 27$ & 268 \\
$I \cdot 78$ & 242 \\
$I \cdot 23$ & 415 \\
$I \cdot 00$ & 540 \\
$(1 \cdot 32 \pm 0 \cdot 28)$ &
\end{tabular}

NADPH
concn
0.70
0.64
0.75
0.57
0.60
0.50
$(0.63 \pm 0.08)$

\begin{tabular}{c} 
NADPH \\
\hline NADP(H) \\
46 \\
58 \\
59 \\
32 \\
49 \\
50
\end{tabular}

Table 5. Influence of dilution rate on nicotinamide cofactor concentrations and ratios in Pseudomonas sp. grown in continuous culture under glucose limitation

Cofactor concentrations ( $\mu \mathrm{mol} / \mathrm{g}$ cell dry wt) and ratios $(\%)$ were measured as described in Methods. Figures in parentheses give average values. Abbreviations as in Table 3.

$\begin{array}{cc}\begin{array}{c}\text { Dilution } \\ \text { rate } \\ \left(\mathrm{h}^{-1}\right)\end{array} & \text { NADH } \\ 0.48 & 0.26 \\ 0.48 & 0.14 \\ 0.40 & 0.11 \\ 0.30 & 0.16 \\ 0.15 & 0.10 \\ 0.08 & (0.15 \pm 0.06)\end{array}$

$\begin{array}{cc}\text { NADH } & \text { NADP(H) } \\ \text { NAD(H) } & \text { concn } \\ 10.0 & I \cdot 04 \\ 5.0 & 0.93 \\ 3.2 & I \cdot 37 \\ 3.3 & 1.49 \\ 1.8 & I \cdot 18 \\ & (1 \cdot 20 \pm 0.23)\end{array}$

\begin{tabular}{c} 
NAD(H) \\
\hline NADP(H) \\
250 \\
301 \\
248 \\
328 \\
458
\end{tabular}

NADPH
concn
0.52
0.41
0.54
0.62
0.55
$(0.53 \pm 0.07)$

\begin{tabular}{c} 
NADPH \\
\hline NADP(H) \\
50 \\
44 \\
39 \\
42 \\
47 \\
$(45 \pm 4)$
\end{tabular}

$2 \mu \mathrm{mol} / \mathrm{g}$ dry wt reported for bacteria by Wimpenny \& Firth (1972). This difference may be related to the use of continuous culture in the present study and maintenance in the culture of a near-saturating air concentration (see Methods; Matin et al., 1976).

\section{Ammonium limitation}

In carbon-limited media, the NADH concentration of cells remained almost the same throughout a fivefold change in total NAD concentration. This is in agreement with the finding of Wimpenny \& Firth (1972) that bacteria grown under different conditions rigidly maintain a constant NADH level. In this connexion, a comparison of cofactor concentrations between bacteria grown in carbon-limited and ammonium-limited media was of interest since the latter grow with an excess of carbon source and could therefore be expected to possess higher levels of reduced cofactors. The $\mathrm{NAD}(\mathrm{H})$ content of the bacteria was not influenced by $D$ in ammonium-limited medium and averaged $3.7 \mu \mathrm{mol} / \mathrm{g}$ dry wt (Table 6 ). NADH and $\operatorname{NADP}(H)$ levels were also uninfluenced by $D$ in this medium. The NADH content of bacteria grown under ammonium limitation was similar to that of bacteria grown under carbon limitation (an average of 0.19 against $0.14 \mu \mathrm{mol} / \mathrm{g}$ dry wt for L-lactatelimited organisms). The NADP(H) content of the organisms grown under each limitation was also similar, but the NADPH concentration and the NADPH : NADP(H) ratio appeared to be somewhat higher in the organisms grown under ammonium limitation. 
Table 6. Influence of dilution rate on nicotinamide cofactor concentrations and ratios in Pseudomonas sp. grown in continuous culture under ammonium limitation

Cofactor concentrations ( $\mu \mathrm{mol} / \mathrm{g}$ cell dry wt) were measured as described in Methods. Figures in parentheses give average values. Abbreviations as in Table 3.

\begin{tabular}{|c|c|c|c|c|c|c|}
\hline $\begin{array}{l}\text { Dilution } \\
\text { rate } \\
\left(\mathrm{h}^{-1}\right)\end{array}$ & $\begin{array}{l}\mathrm{NAD}(\mathrm{H}) \\
\text { concn }\end{array}$ & $\begin{array}{l}\text { NADH } \\
\text { concn }\end{array}$ & $\frac{\mathrm{NADH}}{\mathrm{NAD}(\mathrm{H})}$ & $\begin{array}{l}\text { NADP(H) } \\
\text { concn }\end{array}$ & $\begin{array}{l}\text { NADPH } \\
\text { concn }\end{array}$ & $\frac{\text { NADPH }}{\text { NADP(H) }}$ \\
\hline $\begin{array}{l}0.50 \\
0.38\end{array}$ & $\begin{array}{l}3.5 \\
3.6\end{array}$ & $\begin{array}{l}0.19 \\
0.24\end{array}$ & $\begin{array}{l}5.4 \\
6.7\end{array}$ & 0.76 & $\begin{array}{l}0.51 \\
0.66\end{array}$ & $\begin{array}{l}67 \\
63\end{array}$ \\
\hline 0.25 & 3.6 & 0.26 & $7 \cdot 2$ & $\begin{array}{l}1.4 \\
1 \cdot 24\end{array}$ & $\begin{array}{l}0.95 \\
0.95\end{array}$ & 77 \\
\hline 0.15 & $4 \cdot 0$ & 0.16 & 4.0 & $I \cdot 2 I$ & 0.88 & 73 \\
\hline 0.08 & $\begin{array}{c}3 \cdot 8 \\
(3 \cdot 7 \pm 0.2)\end{array}$ & $\begin{array}{c}0.16 \\
(0.19 \pm 0.05)\end{array}$ & $\begin{array}{c}4 \cdot 2 \\
(5 \cdot 5 \pm 1 \cdot 4)\end{array}$ & $\begin{array}{c}0.82 \\
(1.07 \pm 0.22)\end{array}$ & $\begin{array}{c}0.75 \\
(0.8+0.18)\end{array}$ & $\begin{array}{c}91 \\
(74+11)\end{array}$ \\
\hline
\end{tabular}

\section{DISCUSSION}

A striking feature of the results is the dependence of the NAD(H) pool size of bacteria on $D$ in carbon-limited media. The three limiting-carbon sources used, L-lactate, succinate and glucose, differ in their redox status and, to some extent, in their metabolism by the organism. Succinate is an intermediate of the tricarboxylic acid cycle but lactate and glucose depend on a number of enzymic steps, many of which are linked to nicotinamide cofactors, for their entry into the cycle. Yet, $\mathrm{NAD}(\mathrm{H})$ concentrations were very similar in bacteria grown at a given $D$ on any of the three carbon sources, and in all cases increased with decreasing $D$. Under carbon limitation, therefore, $\mathrm{NAD}(\mathrm{H})$ concentration of bacterial cells was a function entirely of $D$ and was not affected by qualitative changes in the carbon source of the culture. In contrast, batch-culture studies of London \& Knight (I966) and Wimpenny \& Firth (I972) have shown that the NAD level in bacteria can be influenced by culture carbon source. This difference could be due to differences between continuous and batch modes of cultivation. Our results relate to conditions of carbon limitation whereas, in batch cultures, growth occurs mostly in the presence of an excess of nutrients. Moreover, changes in the carbon source of batch cultures often lead to significant changes in specific growth rate and it is conceivable that the alteration in cellular cofactor concentrations found by these workers resulted not from change in the carbon source per se but concomitant change in specific growth rate.

It is not known whether bound or free forms of NAD accounted for the increase in the cofactor concentration with decreasing $D$. Matin et al. (1976) found a parallel increase in an NAD-linked dehydrogenase (L-lactate dehydrogenase) in the same Pseudomonas sp. and NAD bound to this, and perhaps other enzymes, could account for the increase. There is, however, no necessary correlation between the two phenomena since the specific activities of two NADP-linked enzymes (glucose 6-phosphate and isocitrate dehydrogenases) increased with decreasing $D$ (Matin et al., 1976), yet no parallel increase in cellular NADP concentration was found.

In contrast to NAD, NADH concentration in the bacteria did not change in response to changes in the nutritional environment of the culture. The different nutritional environments tested included ammonium-limited medium in which bacteria grew in the presence of an excess of carbon source and might therefore have been expected to possess higher levels of this cofactor. It appears therefore that bacteria tend to maintain a constant NADH level and only the concentration of the oxidized form of this cofactor changes in different growth environments. Similar findings in three facultatively aerobic bacteria led Wimpenny \& 
Firth (I972) to suggest that regulation of oxidation-reduction pathways in bacteria may be geared to maintenance of a constant NADH pool size rather than a constant NADH : NAD ratio. Our results with an obligately aerobic bacterium are consistent with this suggestion.

The need to maintain a constant NADH pool size could account for the observed increase in NAD concentration with decreasing $D$ in bacteria grown in carbon-limited medium. As has been emphasized by Matin et al. (1976), with decreasing $D$, such bacteria can be expected to have progressively lower concentrations of intracellular metabolites including those whose oxidation by NAD-linked dehydrogenases serves as the source of NADH. A concomitant increase in oxidized NAD cofactor level would tend to compensate for this lowered concentration and thereby help maintain a constant NADH pool size. This interpretation is supported by the observation that bacteria grown under ammonium limitation, which can be expected to possess an excess of carbon metabolites at all $D$ values, do not exhibit an increase in NAD concentration with decreasing $D$.

In maintaining a constant NADH level rather than a constant NADH : NAD ratio bacteria differ from eukaryotic organisms in which maintenance of a constant ratio appears to be more important. Our results do not support the reports that the NAD : NADP ratio remains constant in different growth environments (Brody, 1972; McLaren et al., 1973; Manlapaz-Fernandez \& Olivera, 1973): in our bacterium this ratio changed considerably in response to conditions which altered the total NAD concentration.

A rigid control of cellular NADP and NADPH concentrations at constant levels in different growth environments is also suggested by our data. However, the NADPH concentration appeared to be somewhat higher in bacteria grown under ammonium limitation than in those grown under carbon limitation and it may be that constant levels of this cofactor are less critical for regulation of bacterial metabolism than those of NADH.

\section{REFERENCES}

Barnes, L. D., McGuire, J. J. \& Atrinson, E. E. (1972). Yeast diphosphopyridine nucleotide specific isocitrate dehydrogenase. Regulation of activity and unidirectional catalysis. Biochemistry, New York $\mathbf{x I}$, $4322-4328$.

Brody, S. (1972). Regulation of pyridine nucleotide levels and ratios in Neurospora crassa. Journal of Biological Chemistry 247, 6013-6017.

Carrier, P. H. (1968). Dosage des pyridine nucleotides oxydes et reduits dans le sang et les tissues animaux. European Journal of Biochemistry 4, 247-255.

Dionisi, O., Galeotti. T., Terranova, T. \& AZZI, A. (1973). Kinetics of redox changes of nicotinamideadenine dinucleotides in Ehrlich ascites tumor cells. FEBS Letters 30, 84-88.

Hofk, J. B. \& TAger, J. M. (1973). The oxidoreduction state of free NAD(P) and mass-action ratio of total nicotinamide nucleotides in isolated rat liver mitochondria. Biochimica et biophysica acta $225,197$.

LONDON, J. \& KNIGHT, M. (I966). Concentration of nicotinamide nucleotide coenzymes in micro-organisms. Journal of General Microbiology 44, 24 I-254.

Mclaren, J., Ngo, D. T. C. \& Olivera, B. M. (1973). Pyridine nucleotide metabolism in Escherichia coli. III. Biosynthesis from alternate precursors in vivo. Journal of Biological Chemistry 248, 5I44-5149.

Manlapaz-Fernandez, P. \& Olivera, B. M. (1973). Pyridine nucleotide metabolism in Escherichia coli. IV. Turnover. Journal of Biological Chemistry 248, 5150-5I55.

MaRshall, W. E. \& OMACHI, A. (I974). Measured and calculated NAD /NADH ratios in human erythrocytes. Biochimica et biophysica acta 354, I-IO.

Matin, A., Grootjans, A. \& Hogenhuis, H. (1976). Influence of dilution rate on enzymes of intermediary metabolism in two freshwater bacteria grown in continuous culture. Journal of General Microbiology 94, 323-332.

Pina, M. Z., Brunner, A., Desanchez, V. C. \& Pina, E. (1973). Role of the redox state of nicotinamide adenine dinucleotides in the in vivo regulation of inositol biosynthesis in Neurospora crassa. Biochimica et biophysica acta 320, 79-85.

Sanwal, B. D. (1970). Allosteric controls of amphibolic pathways in bacteria. Bacteriological Reviews 34, 20-39. 
Schwartz, J. P., Passonneau, J. V., Johnson, G. S. \& Pastan, I. (1974). The effect of growth conditions on $\mathrm{NAD}^{+}$and $\mathrm{NADH}$ concentrations and $\mathrm{NAD}^{+}: \mathrm{NADH}$ ratio in normal and transformed fibroblasts. Journal of Biological Chemistry 249, 41 38-4143.

WIMPENNY, J. \& FIRTH, A. (1972). Levels of nicotinamide adenine dinucleotide and reduced nicotinamide adenine dinucleotide in facultative bacteria and the effect of oxygen. Journal of Bacteriology IIr, 24-32. 